\title{
TRABALHO, IDENTIDADE E PRODUÇÃO DE SABERES DE PESCADORES ARTESANAIS NO CONTEXTO DA CONSTRUÇÃO DA USINA HIDRELÉTRICA DE TUCURUÍ- PARÁ - ANÁLISE A PARTIR DE UMA COMUNIDADE RIBEIRINHA AMAZÔNICA
}

\author{
LABOR, IDENTITY, AND PRODUCTION OF KNOWLEDGE OF ARTISANAL \\ FISHERMEN IN THE CONTEXT OF THE CONSTRUCTION OF TUCURUÍ-PARÁ \\ HYDROELECTRIC POWER PLANT - ANALYSIS FROM AN AMAZON RIVER \\ COMMUNITY \\ TRABAJO, IDENTIDAD Y PRODUCCIÓN DE SABERES DE PESCADORES \\ ARTESANALES EN EL CONTEXTO DE LA CONSTRUCCIÓN DE LA USINA \\ HIDROELÉCTRICA DE TUCURUI-PARÁ - ANÁLISIS A PARTIR DE UNA \\ COMUNIDAD RIBEREÑA AMAZÓNICA
}

José Carlos Vanzeler Pompeu*

Doriedson do Socorro

Rodrigues**

Alberto Damasceno***

* Mestre em Educação e Cultura pela

Universidade Federal do Pará (UFPA). Membro do Grupo de Estudos e Pesquisas sobre

Trabalho e Educação da UFPA. Belém, Pará, Brasil. E-mail: jcvanzeler@ufpa.br

**Doutor em Educação pela UFPA. Docente do Programa de Pós-graduação em Educação e Cultura e do Programa de Pós-graduação em Currículo e Gestão da Escola Básica na UFPA. Professor Adjunto III do Campus Universitário do Tocantins/Cametá - UFPA. Membro do Grupo de Estudos e Pesquisas sobre Trabalho e Educação da UFPA. Belém, Pará, Brasil. E-mail: doriedson@ufpa.br

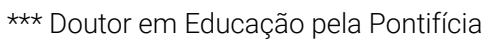
Universidade Católica de São Paulo (PUC-SP). Docente do Programa de Pós-graduação em Currículo e Gestão da Escola Básica da UFPA. Professor Titular da UFPA. Coordenador do Laboratório de Pesquisas em Memória e História da Educação e do Grupo de Estudos em Educação no Pará na Primeira República. Belém, Pará, Brasil. E-mail: albertod@ufpa.br Recebido para publicação em 1.5.2018 Aprovado em 8.3.2019

\section{Resumo}

Analisam-se processos de formação de identidade e produção de saberes de pescadores artesanais de uma comunidade ribeirinha do município de Cametá-PA, com base no materialismo histórico-dialético e em dados obtidos por meio de entrevista semiestruturada e observação participante. Os resultados apontam que a construção da Usina Hidrelétrica de Tucuruí teve impactos negativos na materialidade produtiva dos pescadores, implicando produção de saberes de enfrentamento e de alinhamento à lógica do capital, como mercantilização da produção e estabelecimento de relações patronais nas experiências de trabalho.

Palavras-chave: Identidade. Pescadores artesanais. Saberes. Trabalho.

\section{Abstract}

Processes of identity formation and knowledge production of artisanal fishermen from a riverine community in the municipality of Cametá-PA are analyzed, based on historical-dialectical materialism and data obtained through a semi-structured interview and participant observation. 
The results indicate that the construction of the Tucurui Hydroelectric Power Plant negatively affected the productive materiality of the fishermen, implying the production of knowledge of confronting and alignment with the logic of capital, as commodification of production and establishment of employer relations in work experiences.

Keywords: Identity. Artisanal fishermen. Knowledge. Work.

\section{Resumen}

Se analizan procesos de formación de identidad y producción de saberes de pescadores artesanales de una comunidad ribereña del municipio de Cametá-PA, basado en el materialismo histórico-dialéctico y en datos obtenidos por medio de entrevista semiestructurada y observación participante. Los resultados apuntan que la construcción de la Usina Hidroeléctrica de Tucuruí impactó negativamente a la materialidad productiva de los pescadores, implicando en la producción de saberes de enfrentamiento y de alineamiento a la lógica del capital, como mercantilización de la producción y establecimiento de relaciones patronales en las experiencias de trabajo.

Palabras clave: Identidad. Pescadores artesanales. Saberes. Trabajo.

\section{Introdução}

O presente estudo ${ }^{1}$ analisa processos de formação de identidade ${ }^{2}$ em interlocução com a produção de saberes do trabalho da pesca artesanal ${ }^{3}$. O objeto de investigação é a formação da identidade dos pescadores artesanais ${ }^{4}$ da ilha do Tentém ${ }^{5}$, município de Cametá-PA, a partir das condições materiais de produção de saberes do trabalho da pesca no contexto da construção da Usina Hidrelétrica de Tucuruí (UHE), localizada no Rio Tocantins, município de Tucuruí, sudeste do Pará, separada por aproximadamente 310 quilômetros de Belém, capital do estado do Pará.

A Usina Hidrelétrica de Tucuruí ${ }^{6}$ é considerada a maior hidrelétrica genuinamente nacional, segundo a agência de notícias ambientais EcoAgência. O projeto para sua implantação teve início no ano de 1973, em plena ditadura militar, mas a obra só foi entregue em 1984, durante o governo militar de João Figueiredo. A extensão total da área da usina é de $3.007 \mathrm{~km}$, sendo comparada a 304 campos de futebol, e foi construída antes da lei que exige a realização de Estudo de Impacto Ambiental (EIA) para o início da obra, sendo que esse foi elaborado simultaneamente à sua construção, sem quase nenhuma influência. Assim, o alcance do lago foi imprevisível e, na época, milhares de pessoas tiveram de sair às pressas de suas casas, pois a água já estava próxima. A barragem deslocou cerca de 32 mil pessoas e, há mais de 30 anos, elas lutam por seus direitos.

Segundo Silva (2003, p. 1), a construção da UHE de Tucuruí causou inúmeros impactos nas ilhas dos municípios que ficam à jusante da barragem, entre eles, Cametá, sendo percebidos pela população, conforme Barra e Furtado (2004, p. 64), ao constatarem mudanças na qualidade ambiental das ilhas, como a baixa produtividade 
dos solos de várzea, que implicou a queda da produção de frutos, como o cacau e o açaí; o desaparecimento de várias espécies de peixes e a diminuição acentuada dos cardumes de mapará (peixe nativo da região); a poluição da água; e o assoreamento do rio Tocantins, aumentando consideravelmente as doenças.

Esses impactos corroboraram para processos de mudança7 na produção de saberes do trabalho da pesca, partindo do pressuposto de que esses saberes são produzidos de acordo com as condições materiais dos pescadores. Sendo assim, havendo mudanças nas condições materiais de produção dos saberes do trabalho da pesca, entende-se que ocorreram, também, mudanças na identidade do pescador artesanal.

A análise da identidade se faz por meio da corrente materialista-histórica, por meio da qual a identidade é entendida como resultado das sínteses materiais humanas ao longo do tempo, uma vez que os pescadores artesanais materializam identidades não como condição de expressão do seu modo tradicional e peculiar de vida, mas como sendo o resultado de múltiplas determinações que são forjadas no interior societário das relações de contradição e negação vividas por esses sujeitos.

Nessa perspectiva, entende-se a identidade como resultado de processos que alteram a identificação dos indivíduos em decorrência de transformações maiores na organização econômica, política e simbólica das relações sociais (DUBAR, 2009, p. 26).

É importante frisar que as condições materiais de existência dos pescadores são forjadas por meio do trabalho da pesca artesanal (realizado por meio dos saberes). Parte-se do pressuposto de que é por meio do trabalho que o pescador constitui sua subjetividade e tece sua identidade.

0 trabalho também constrói sua identidade
Rodrigues (2012, p. 140) lembra que, segundo Marx (2008), é o trabalho que funda as relações humanas e cria as condições materiais para a existência. Ao mesmo tempo, o trabalho também constrói sua identidade, ou um conjunto de representações sociais em comum que faz as pessoas se integrarem na esfera coletiva, pois se percebem envolvidas em atividades similares (tanto em suas manifestações concretas como abstratas). Na concepção concreta do trabalho, a pessoa encontra as condições para sua humanização, pois produz cultura, saberes e condições para sua existência física. Já o objeto abstrato do trabalho são as razões políticas para o envolvimento social de uma classe que visa à superação de modos de produção excludentes, próprios do capitalismo.

Atualmente, percebe-se a incidência de uma desestruturação do trabalho da pesca artesanal, causada, muitas vezes, pela própria dinâmica do avanço do capital de outros setores de produção industrial que são poluentes e por isso causam o empobrecimento biológico do ambiente, das empresas madeireiras, da expansão turística etc. Em Cametá, um dos mais fortes impulsos para a desorganização do trabalho da pesca nas comunidades de pescadores artesanais foi a construção da UHE, iniciada em 1973. Ela forçou o pescado a migrar para outras áreas, causando mudanças significativas na forma como os pescadores desenvolviam seu trabalho a fim de buscar condições materiais de existência. 
Magalhães (2012, p. 13) observa que, quanto à organização socioeconômica anterior à barragem, sua construção significou a desestruturação da pesca e da agricultura praticada nas várzeas e ilhas, em especial no trecho do rio que se estende de Baião e atravessa Mocajuba, Igarapé-Miri e Limoeiro do Ajuru, municípios também do nordeste paraense, próximos a Cametá.

A construção da UHE de Tucuruí teve impacto direto na zona ribeirinha de Cametá, uma vez que essa se encontra no rio Tocantins, o qual faz parte da área de jusante da barragem. Entre os impactos estavam as constantes inundações que ocorriam fora do período de inverno regional, causando alagamentos de áreas de criação de animais para consumo próprio e de cultivo de pequenas hortas familiares, ou seja, as culturas de várzea, causando, assim, a desorganização dos espaços em que viviam os moradores das ilhas fluviais do Baixo Tocantins (SILVA, 2003. p. 3).

O objetivo deste trabalho, portanto, foi problematizar as mudanças ocorridas nos modos de vida dos pescadores artesanais da ilha do Tentém, Cametá-PA, no contexto da construção da UHE de Tucuruí. Essas mudanças estão relacionadas às condições materiais de existência desses sujeitos, a partir das quais se dá a produção de saberes do trabalho da pesca, os quais corroboram para processos de formação da identidade do pescador artesanal.

\section{Metodologia}

Para melhor compreensão do objeto em estudo e sua relação dialética com os demais elementos apresentados, esta pesquisa foi pautada na abordagem qualitativa. O sujeito e o objeto desta pesquisa estão em inteira atuação, de modo que a busca aqui é da compreensão, e não da visão terminalista da explicação. Assim, é necessário empreender a análise dos aspectos ideológicos, teóricos, metodológicos e técnicos inter-relacionados no conjunto dos fatos históricos próprios de cada cenário a ser pesquisado (MARQUES, 1997, p. 22).

Como instrumento de coleta de dados, foi utilizada a entrevista semiestruturada, que, segundo Bogdan e Biklen (1994), é uma técnica que permite relacionar teoria aos conhecimentos investigados daquela realidade, bem como proporciona uma interação entre quem pesquisa e quem é pesquisado. Essa interação é mediada pelo dialogismo, de tal forma que se aproximem de uma conversa, podendo, assim, contribuir para um clima de confiança, que irá propiciar a geração de informações importantes.

As entrevistas, de acordo com Alves-Mazzotti e Gewandsznajder (2000, p. 168), assemelham-se muito a uma conversa, pois o investigador está interessado em entender o significado que os sujeitos dão a eventos, situações, processos ou personagens que fazem parte de seu cotidiano. Isso garantiu maior interação no momento das conversas, o que fez que os pescadores ficassem bem mais à vontade para relatar um conjunto de experiências que possuem, bem como falar sobre os saberes que produzem para o trabalho com a pesca artesanal e para os enfrentamentos da vida cotidiana. 
Sendo assim, as entrevistas semiestruturadas foram realizadas com pescadores artesanais da ilha do Tentém, município de Cametá, como forma de coleta de dados que se aproximem da realidade em uma perspectiva interacionista, isto é, a partir de um diálogo aberto com os pescadores. As perguntas foram lidas de forma espontânea e as respostas dos pescadores, gravadas em equipamento específico de gravação. Foram feitas perguntas abertas, que permitiam aos pescadores se expressarem de forma livre, sem sugestões do entrevistador que induzissem às respostas, porém, havendo sempre a mediação e/ou repetição das perguntas.

Investigou-se 0 que têm a dizer as palavras que os pescadores artesanais produzem em suas relações sócio-históricas

Para isso, foram entrevistados sete pescadores que praticam ou já praticaram atividade de pesca artesanal na ilha do Tentém, sendo dois com idade superior a 60 anos e cinco com idades de 21 a 48 anos de idade.

A pesquisa também envolveu a observação participante (BOGDAN; BIKLEN, 1994), como técnica de investigação que usualmente se complementa com a entrevista semiestruturada. A observação participante requereu um contato direto do pesquisador com os atores sociais investigados. Esse contato permitiu uma visão mais ampla do objeto investigado e uma análise mais realista das entrevistas realizadas.

Ao fim do percurso metodológico, os dados foram submetidos à análise de conteúdo na perspectiva de Franco (2012), que tem como característica a superação da visão tecnicista e neutra da tradição positivista, analisando-se os dados em toda sua complexidade histórica e social, entre sujeitos também situados e organizados sócio-historicamente em um determinado espaço e contexto histórico. Com base em Franco (2012), investigou-se o que têm a dizer as palavras que os pescadores artesanais produzem em suas relações sócio-históricas, observando-as em suas recorrências nas entrevistas e sistematizando-as quanto a repetições temáticas, tomando a mensagem verbal como ponto de partida para a investigação, por compreender que são expressão de representações sociais "[...] na qualidade de elaborações mentais construídas socialmente, a partir da dinâmica que se estabelece entre atividade psíquica do sujeito e o objeto do conhecimento" (FRANCO, 2012, p. 12).

Assim, foi possível analisar como os elementos formadores da identidade do pescador artesanal de Cametá sofreram mudanças, voltando-se para processos de resistência frente ao capital, e quais elementos voltaram-se para o conformismo e a manutenção da ordem do capital.

\section{O locus da pesquisa: a llha do Tentém, município de Cametá-PA}

Em meio às singularidades do cenário amazônico, mais precisamente na região do Baixo Tocantins ${ }^{8}$, escolheu-se como locus da pesquisa a ilha do Tentém ${ }^{9}$, localizada no distrito de Juaba ${ }^{10}$, no município de Cametá-PA. 
A constituição histórica da ilha do Tentém teve como base a criação de uma comunidade cristã no ano de 1976. Segundo as informações prestadas pelos pescadores da ilha, durante as entrevistas, a comunidade do Tentém congrega outras comunidades cristãs, como a de Pacovatuba, Muruacá, Mutuacá, Caripí, Fazenda, Ilha Grande de Juaba, Turema, Acarí e Furtado, sendo ilhas próximas a Tentém.

Os dados coletados sobre a ilha do Tentém, durante a pesquisa de campo, partiram dos relatos dos pescadores, do líder da comunidade cristã e do agente de saúde local, que atende a maior parte das famílias da ilha. Foram realizadas entrevistas e analisados documentos fornecidos por eles, uma vez que o Instituto Brasileiro de Geografia e Estatística (IBGE) e a Prefeitura Municipal de Cametá não puderam informar dados detalhados da ilha com a justificativa de que esses são filtrados apenas por distritos.

Segundo os pescadores, a comunidade teve início no ano de 1976 e possuía em torno de 30 famílias. Atualmente, é composta em média por 413 famílias, segundo dados do agente de saúde local. Ele contabiliza que essas famílias possuem o total de 1.731 pessoas, sendo 980 mulheres e 751 homens. Do total de habitantes, 867 são filiados ou associados a entidades representativas, associações e sindicatos, seja como pescadores, seja como trabalhadores rurais, conforme a tabela abaixo:

\section{Tabela 1 - Número de filiados/associados por organização representativa}

\begin{tabular}{l|r}
\hline ENTIDADES REPRESENTATIVAS DE PESCADORES & N. DE FILIADOS \\
\hline Colônia de Pescadores Z-16 de Cametá & 700 \\
\hline ASSOCIAÇÕES DE PESCADORES & N. DE FILIADOS \\
\hline Associação dos Pescadores e Pescadoras Artesanais do Município de Cametá (Apamuc) & 38 \\
\hline $\begin{array}{l}\text { Associação de Preservação Ambiental e Desenvolvimento Sustentável da Ilha Cacoal } \\
\text { (Apadic) - Cametá }\end{array}$ & 49 \\
\hline $\begin{array}{l}\text { Sindicato dos Trabalhadores da Agricultura Familiar, Aquicultores e Pescadores } \\
\text { Artesanais do Município de Cametá (Sinafapac) }\end{array}$ & 27 \\
\hline SINDICATOS DE TRABALHADORES RURAIS & N. DE FILIADOS \\
\hline Sindicato dos Trabalhadores Rurais (STR) - Cametá & 53 \\
\hline Pescadores filiados/associados & 814 \\
\hline Trabalhadores rurais associados & 53 \\
\hline Pescadores e trabalhadores rurais filiados/associados & 867 \\
\hline
\end{tabular}

Fonte: Elaborado pelos autores.

Os dados da Tabela 1 apresentam 814 moradores, quase a metade dos moradores da ilha do Tentém, na situação de filiados/associados a organizações representativas de pescadores. Isso demonstra que os moradores da comunidade são afeitos ao trabalho da pesca artesanal, uma vez que o domínio desses saberes é condição necessária para filiação/associação em organização representativa de pescadores. 
Considerando que a idade mínima para filiação/associação é 18 anos e que, segundo os pescadores, o ofício da pesca é passado dos pais para os filhos ainda jovens, pode-se dizer que a maioria dos habitantes da ilha do Tentém desenvolve atividade de pesca artesanal, fator que justifica a importância dessa ilha para o estudo em questão.

Outro fato que torna a localidade importante para esta pesquisa é que a ilha, entre outras pertencentes ao município de Cametá, foi afetada pela construção da UHE de Tucuruí, conforme relatam os entrevistados:

Depois da construção da Usina Hidrelétrica de Tucuruí, veio a seca do rio. Vocês podem observar que agora, por aqui, há apenas praia; antes, aqui, o rio era fundo. Lá onde eu moro você atravessa de um lado para o outro do rio a pé, em maré baixa.

(Pescador 1).

Hoje, se fosse só da pesca, você não conseguiria sobreviver. Depois da construção da hidrelétrica, o pescado só dá longe daqui e a maioria dos pescadores não tem condições de manter geleiras para ir buscar o pescado; já no passado, antes da construção da hidrelétrica, você conseguia sobreviver só da pesca.

(Pescador 4).

Mesmo antes da construção da UHE, esses sujeitos já viviam em situação de negação de necessidades básicas. Hoje em dia, os pescadores artesanais, não apenas da ilha do Tentém, mas de todo o Brasil, contam com leis e programas do governo federal que os ajudam a superar essa situação de negação, como a Lei n. 10.779, de 25 de novembro de 2003, que concede o Benefício de Seguro Desemprego do Pescador Artesanal, durante o período de defeso (época de reprodução das espécies), ao pescador profissional que exerce a atividade pesqueira de forma artesanal.

\section{A formação de identidade dos pescadores artesanais da ilha do Tentém, município de Cametá-PA: elementos voltados para resistência frente ao capital, materializado na construção da UHE de Tucuruí-PA}

Entende-se aqui por resistência as atitudes dos pescadores relacionadas à busca do enfrentamento da realidade negativa imposta ao meio natural e às relações de trabalho, pela construção da UHE de Tucuruí. São atitudes que envolvem processos de transformação da natureza por meio de criação de saberes, organização individual e coletiva do trabalho da pesca, e outras que possam ser úteis para emancipação dos pescadores.

Com relação à criação de saberes como forma de resistência ao capital, a fala do Pescador 2, de 54 anos, enfatiza essas mudanças, informando que as práticas de pesca mais comuns antes da construção da UHE eram a "rede e o "caniço", e que hoje é a "malhadeira e a "espingarda". 
Naquele tempo, nós usávamos na maioria das vezes a rede para bloquear e o caniço para pescar. Aí você saía com o caniço de manhã e pouco tempo depois já voltava com o almoço. Agora o modo de pescar mudou, utilizamos a todo tempo a malhadeira, a espingarda para pescar no fundo, com a qual pescamos qualquer tipo de peixe.

A malhadeira era um saber já presente na cultura da pesca artesanal na ilha do Tentém, mas que passou a ser usada com intensidade após a construção da UHE. Já a espingarda foi um saber criado para se adaptar à nova realidade da pesca, que agora necessitava de aparatos que permitissem pescar variadas espécies de peixes em locais de difícil acesso.

A filiação dos pescadores a colônias, associações e sindicatos é a manifestação da práxis social na dimensão política

Ou seja, a incorporação e intensificação de instrumentos de pesca nas atividades laborais se constituíram em estratégias para que o ser social pescador artesanal continuasse existindo como unidade teórico-prática. Do contrário, não exercendo a pesca, haveria sujeitos com o domínio de um saber pescar, mas sem o exercício efetivo da pesca, dada a dificuldade para se exercer o ofício em decorrência dos impactos negativos da construção da UHE.

Outro elemento de resistência evidenciado na pesquisa é a filiação dos pescadores artesanais em entidades representativas de trabalhadores. Na ilha do Tentém, os pescadores artesanais são filiados em colônias e associações de pescadores - na Colônia de Pescadores Z-16 de Cametá, são ao todo 700 filiados; as associações como Apamuc, Apadic e Sinafapa somam 114 filiados, segundo os pescadores. Ao todo, são 814 pescadores filiados a entidades representativas, de um total de 1.731 habitantes que residem na ilha, ou seja, quase a metade dos moradores.

A filiação dos pescadores a colônias, associações e sindicatos é a manifestação da práxis social na dimensão política, a qual pressupõe a "organização sociopolítica real de seus membros" (VÁZQUEZ, 1968, p. 200), desempenhando, nesse sentido, importante papel os saberes do trabalho da pesca como elementos estruturantes dessa organização. Em termos empíricos, por exemplo, trabalhadores de pesca artesanal da Amazônia, envolvidos em sua realidade político-social, produzem saberes sociais em seu meio político, que são responsáveis pela implementação e fortalecimento de sua formação como movimento social, organizações dos tipos "colônia", "associações", "sindicatos", possuindo tais saberes uma dupla configuração: elementos estruturantes da organização e por ela também estruturados, elaborados (RODRIGUES, 2012, p. 64). Ainda segundo Rodrigues (2012):

[...] pressupomos que trabalhadores de pesca artesanal da Amazônia, envolvidos em sua realidade político-social, produzem saberes sociais dos tipos políticos, relacionais, organizacionais, conjunturais, atitudinais, por exemplo, responsáveis pela implementação e fortalecimento de sua formação enquanto movimento social - enquanto organização do tipo 'Colônia' -, possuindo 
tais saberes uma dupla configuração: elementos estruturantes da organização e por ela também estruturados, elaborados, atuando como elementos constituidores de uma consciência de classe para si (RODRIGUES, 2012, p. 82, grifo do autor).

Assim, considera-se que a filiação dos pescadores a entidades representativas constitui mecanismos de resistência frente às condições impostas a esses trabaIhadores. Sendo assim, fazer parte de uma entidade representativa demonstra a formação da consciência de pertencimento a uma classe de trabalhadores, neste caso, a classe dos pescadores artesanais.

\section{A formação de identidade dos pescadores artesanais da ilha do Tentém, município de Cametá-PA: elementos voltados para o conformismo frente ao capital, materializado na construção da UHE de Tucuruí-PA}

Por conformismo, tem-se a aceitação da realidade negativa imposta aos pescadores pela construção da UHE, no sentido de alinharem-se ao sociometabolismo do modo de produção capitalista, ou seja, processos de realização do trabalho da pesca que promoveram a desorganização dos pescadores como classe, e processos que perpassaram a busca por valores de uso e buscaram a mercantilização da produção, assim como atitudes que, mesmo indiretamente, concorreram para processos de exploração do trabalho no interior da ilha.

Um dos achados da pesquisa com relação aos elementos de conformismo reside na constatação de que a pesca, que antes era feita quase sempre de forma coletiva, após a UHE passou a ser feita de forma individual, sendo raras exceções a pesca coletiva, conforme relata o Pescador 1 :

Antes, na pesca da rede era um grupo de pessoas que se reuniam para pescar. Hoje, é individual, cada um pesca pra si. É raro, mas, às vezes, quando decidimos ir pescar longe da ilha, aí vão, dois, três pescadores juntos, mas é muito difícil acontecer isso.

Essa perda da coletividade no trabalho da pesca artesanal isola os pescadores da troca de experiências, do compartilhamento dos saberes e, consequentemente, de uma organização como classe, uma vez que, segundo Rodrigues (2012), é por meio do trabalho coletivo que os trabalhadores agem sobre a natureza, mantêm relação com ela e com os homens e, dessa forma, mantêm relações sociopolíticas como luta de classes, pois formam juntos uma consciência sobre a realidade em que vivem e assim modificam a si próprios. O autor também lembra Gramsci (1984), que concebe o trabalho como princípio educativo, inferindo-se que a construção da UHE corroborou para um processo formativo em que o individual vem se sobrepondo ao coletivo, em termos de realização de atividades produtivas.

Acrescida essa questão, destaque-se que a fragmentação do trabalho da pesca na ilha de Tentém contribuiu também para o surgimento de atitudes individuais de pes- 
ca predatória e descumprimento de acordos de preservação ambiental. Segundo os pescadores, não há uma conscientização por parte de muitos pescadores no que tange à preservação do pescado na ilha, tal qual o exposto pelo Pescador 2.

[...] vou lembrar um episódio que aconteceu mês de setembro. Fizeram um bloqueio grande lá para fora, para frente do rio, pegaram tainha que estavam 'até o gogó' de ovas [repleta de ovas]. Então, se eles tivessem a consciência de não pegar aquele peixe, aí teríamos muitos peixes na ilha.

Vê-se, com isso, que a materialização do capital, por meio da construção da UHE, também impactou as relações sócio-organizacionais dos pescadores, com relação aos acordos de pesca, uma vez que se intensificou um discurso preservacionista, conformando, contraditoriamente, esses sujeitos a uma situação de culpabilidade pela falta do pescado na região, levando-os a uma preservação que implicou luta entre conscientes e não conscientes, desconsiderando-se que a falta de peixes foi situação criada pela construção da Usina Hidrelétrica de Tucuruí, estando, isto sim, os pescadores na condição de impactados por esse projeto.

Apoiados em Marx (1998), para quem as ideias dominantes acabam sendo assumidas pelos dominados como se eles próprios as tivessem produzido, entende-se aqui que os pescadores acabaram assumindo, com esse discurso, o ônus pela falta de peixe na região e relações sociais de luta entre si, dadas as condições materiais devastadoras da existência advindas do projeto da hidrelétrica.

Outro elemento de conformismo que se destaca é a aquisição de geleiras para a busca do pescado em longas distâncias e sua conservação, as quais, por terem alto custo, são de propriedade de poucos pescadores e, sendo assim, passou a haver relações patronais entre os pescadores na ilha do Tentém, isto é, relações de compra e venda de mão de obra para operar as geleiras.

Hoje você não consegue mais sobreviver da pesca, antes, sim. Por que muitos pescadores 'pequenos' não têm condições de fazer, de manter geleiras grandes para ir buscar longe o pescado, que agora está muito longe. Antes, o pescado era abundante, antes, a gente conseguia viver da pesca (Pescador 4).

Vê-se, portanto, que os pescadores que possuem geleiras para pesca em longas distâncias passaram a estabelecer relações patronais com outros pescadores, pagando pelos serviços dos demais pescadores a partir da intensificação do uso de maquinaria, as geleiras, para aumentar a produção voltada para a mercantilização em oposição à pesca com valor de uso, corroborando para que o trabalhador pescador se constituísse em propriedade de relações capitalistas, havendo, assim, um domínio do capital sobre o trabalho desses sujeitos, conforme relato, ainda, do Pescador 4:

[...] Além disso, você precisa ter uma geleira, para após pegar o pescado, poder gelar e conservar, senão você perde o peixe [...] a maioria dos pescadores não tem condições de manter geleiras pra ir buscar o pescado. 
Nesse sentido, o trabalho da pesca artesanal como elemento fundante das relações entre os pescadores, e que demarca identidade desses sujeitos, passa a ser condicionado pelo capital. O capitalismo traz consigo uma série de contradições, muitas delas relacionadas ao mundo do trabalho. Ao mesmo tempo que o trabaIho é a fonte de humanização e é o fundador do ser social, sob a lógica do capital, torna-se degradado, alienado, estranhado. O trabalho perde a dimensão original e indispensável ao homem de produzir coisas úteis (que visariam satisfazer às necessidades humanas), para atender às necessidades do capital. Sob o capitalismo, explicou Marx (2008), o trabalhador decai à condição de mercadoria e a sua miséria está na razão inversa da magnitude de sua produção.

\section{Considerações finais}

A pesquisa sobre a pesca artesanal na ilha do Tentém, município de Cametá, representa uma realidade de todo o Baixo Tocantins, em municípios como Limoeiro do Ajurú, Baião, Mocajuba, Oeiras do Pará, os quais foram atingidos pela construção da UHE de Tucuruí.

Um dos desastres causados pela construção da UHE foi o desaparecimento de peixes, mudanças nos ciclos hidrológicos, entre outros, que fizeram a pesca já não ser mais uma profissão que garanta o sustento dos pescadores. Nas entrevistas e nas observações realizadas durante a pesquisa, observa-se o quanto a construção desse projeto afetou de forma negativa o modo de vida dos pescadores artesanais da ilha, que se viram obrigados a realizar mudanças nos seus modos de vida, principalmente, na produção de saberes.

A partir da produção de saberes, os pescadores criaram mecanismos de enfrentamento dessas condições. No entanto, percebe-se que, em determinadas situações, alinharam-se à lógica do capital, estabelecendo processos de mercantilização da produção e de relações patronais no interior da ilha.

Assim, pode-se afirmar que a identidade do pescador artesanal da ilha do Tentém possui uma formação caracterizada pelo distanciamento do trabalho da pesca como atividade criadora de valores de uso e que garanta suas condições materiais de existência, tornando-o dependente de programas sociais do governo federal, como o seguro defeso, para custear suas necessidades vitais.

\section{Notas}

1Trata-se de recorte da dissertação "Saberes do Trabalho e Formação de Identidade de Pescadores Artesanais no Município de Cametá-Pará", sob orientação do Prof. Dr. Doriedson do Socorro Rodrigues (PPGEDUC/UFPA) e coorientação do Prof. Dr. Raimundo Alberto de Figueiredo Damasceno (PPEB/UFPA), defendida em 2017 no Programa de Pós-graduação em Educação e Cultura (PPGEDUC) da Universidade Federal do Pará. 
2 Esta pesquisa analisa a formação de identidade a partir do materialismo histórico-dialético, considerando os processos de produção dos saberes do trabalho da pesca artesanal como elementos por meio dos quais os sujeitos vão, historicamente, construindo suas singularidades, de modo que, por meio do trabalho da pesca, materializado também em saberes, os pescadores formam sua subjetividade.

${ }^{3}$ Consideram-se aqui os saberes do trabalho como aqueles produzidos, mobilizados e modificados em situação de trabalho (FRANZOI; FISHER, 2015, p. 148). São técnicas que os pescadores usam "[...] para modificar, comparar, diluir e reatualizar seus conhecimentos a fim de obter êxito nas pescarias [...]" (MORAES, 2007, p. 20); em termos de formação identitária, são "[...] modos de identificação historicamente variáveis [...]" (DUBAR, 2009, p. 13).

${ }^{4}$ No âmbito da Secretaria Especial da Aquicultura e da Pesca da Presidência da República SEAP (BRASIL, 2004), pescador profissional na pesca artesanal é "[...] aquele que, com meios de produção próprios, exerce sua atividade de forma autônoma, individualmente ou em regime de economia familiar ou, ainda, com auxílio eventual de outros parceiros, sem vínculo empregatício".

5 Tentém é uma ilha localizada na zona rural do município de Cametá-PA e compõe um arquipélago de ilhas do município. É formada por área de várzea onde se constroem casas de madeira, geralmente nas margens dos rios.

${ }^{6}$ Sobre a Usina Hidrelétrica de Tucuruí, informações obtidas em: <http://www.ecoagencia.com.br>. Acesso em: 29 mar. 2016.

7 O conceito de "mudança" na produção de saberes do trabalho da pesca volta-se, neste trabalho, para processos históricos e relações interpessoais, que determinaram novos direcionamentos técnicos, produtivos, organizativos e político-ideológicos no modo de vida dos pescadores artesanais da ilha do Tentém, município de Cametá.

8 O território Baixo Tocantins-PA abrange uma área de $36.024,20 \mathrm{~km}^{2}$ e é composto por onze municípios: Abaetetuba, Acará, Baião, Barcarena, Cametá, Igarapé-Miri, Limoeiro do Ajuru, Mocajuba, Moju, Oeiras do Pará e Tailândia. A população total do território é de 739.881 habitantes, dos quais 390.579 vivem na área rural, o que corresponde a 52,79\% do total. Possui 32.365 agricultores familiares, 24.701 famílias assentadas, dez comunidades quilombolas e duas terras indígenas. Seu Índice de Desenvolvimento Humano Médio é 0,68. Fonte: Sistema de Informações Territoriais (BRASIL, 2017).

${ }^{9}$ Rio e ilha localizados no distrito de Juaba, município de Cametá-PA. O topônimo deriva de um passarinho canoro, de coloração preta e peito amarelo, chamado Tem-tem, abundante na localidade. No dicionário eletrônico Houaiss da Língua Portuguesa, a palavra é um substantivo masculino que tem a designação comum erva-de-passarinho. Em Cascudo (1972, p. 861) encontra-se o nome de um pássaro chamado Tem-Tenzinho, conhecido por cauré, caurê, coleirinha, caburé e cauaré. Cauré = Caá - mato; buré por poré - morador. Morador do mato, porque procura ha- 
bitualmente as selvas, fugindo da vizinhança dos centros populosos, bem como os índios que habitavam tal região, os caamutá (Caá - mato; muta - escada, degrau).

10 Os distritos, no contexto do município de Cametá-PA, são considerados subdivisões da zona rural, constituídos de ilhas e áreas de terra firme.

\section{Referências}

ALVES-MAZZOTTI, Alda Judith; GEWANDSZNAJDER, Fernando. 0 método nas ciências naturais e sociais: pesquisa quantitativa e qualitativa. 2. ed. São Paulo: Pioneira, 2000.

BARRA, Jose Domingos Fernandes; FURTADO, Gislane Damasceno. Pescadores artesanais de Cametá: formação histórica, movimento e construção de novos sujeitos. Cametá, PA: [s. n.], 2004.

BOGDAN, Roberto C.; BIKLEN, Sari Knopp. Investigação qualitativa em educação: uma introdução à teoria e aos métodos. Porto: Porto Editora, 1994.

BRASIL. Secretaria Especial de Aquicultura e Pesca. Instrução normativa n. 3, de 12 de maio de 2004. Brasília, DF: Secretaria Especial de Aquicultura e Pesca, 2004. Disponível em: http://sinpesq.mpa.gov.br/rgp_cms/images/publico/CGRA/ instrucao_normativa_03_de_12mai04-rgp.pdf. Acesso em: 29 mar. 2016.

BRASIL. Ministério da Agricultura. Sistema de informações territoriais. Brasília, DF: Ministério da Agricultura, 2017. Disponível em: http://sit.mda.gov.br. Acesso em: 8 ago. 2017.

CASCUDO, Luis da Câmara. Dicionário do folclore brasileiro. Rio de Janeiro: Tecnoprint, 1972.

DUBAR, Claude. A crise das identidades: a interpretação de uma mutação. Trad. Mary Amazonas Leite de Barros. São Paulo: EdUSP, 2009.

ECOAGÊNCIA. Usina Hidrelétrica de Tucuruí: 25 anos de descaso e omissão. EcoAgência, [s. I.], 25 maio 2009. Disponível em: http://www.ecoagencia.com. br/?open=noticias\&id===AUUJIVW5mTHNIRaVXTWJVU. Acesso em: 29 mar. 2016.

FRANCO, B. Análise de conteúdo. Brasília, DF: Líber Livro, 2012.

FRANZOI, Naira Lisboa; FISCHER, Maria Clara Bueno. Saberes do trabalho: situando o tema no campo trabalho-educação. Trabalho Necessário, Niterói, ano 13, n. 20, p. 147-172, 2015. 
GRAMSCI, A. Os intelectuais e a organização da cultura. Rio de Janeiro:

Civilização Brasileira, 1984.

MAGALHÃES, S. B. et al. Transformações sociais e territoriais no ambiente rural da Amazônia Oriental. In: ENCONTRO NACIONAL DA ANPPAS, 6., 2012, Belém. Anais. Belém: [s. n.], set. 2012.

MARQUES, Waldemar. O quantitativo e o qualitativo na pesquisa educacional. Avaliação: revista da avaliação da educação superior, Sorocaba, v. 2, n. 3, p. 19-23, 1997.

MARX, Karl. O capital: crítica da economia política. Rio de Janeiro: Civilização Brasileira, 2008. v. 1.

MARX, Karl; ENGELS, Friedrich. A ideologia alemã. Tradução: Luís Cláudio de Castro e Costa. São Paulo: Martins Fontes, 1998.

MORAES, Sérgio Cardoso de. Uma arqueologia dos saberes da pesca: Amazônia e Nordeste. Belém: EDUFPA, 2007.

POMPEU, José Carlos Vanzeler. Saberes do trabalho e formação de identidade de pescadores artesanais no município de Cametá-Pará. Dissertação (Mestrado em Educação e Cultura) - Programa de Pós-Graduação em Educação e Cultura, Universidade Federal do Pará, Cametá, 2017.

RODRIGUES, Doriedson do Socorro. Saberes sociais e luta de classes: um estudo a partir da Colônia de Pescadores Artesanais Z-16, Cametá/Pará. Belém: [s. n.], 2012.

SILVA, Maria das Graças da. O reordenamento sócio-territorial na área da UHE Tucuruí: o caso da pesca no Baixo Tocantins (Pará/Brasil).

[S. I.]: Sociedade Brasileira de Sociologia, 2003. Disponível em: http://www. sbsociologia.com.br/portal/index.php?option=com_docman\&task=doc_ download\&gid=1164\&ltemid=171. Acesso em: 21 out. 2015.

VÁZQUEZ, Adolfo Sánchez. Filosofia da praxis. São Paulo: Expressão Popular, 1968.

\section{Fontes consultadas}

WILLIAMS, Raymound. Cultura e materialismo. São Paulo: Editora UNESP, 2011. 